\title{
Relationship Between Quality of Life and Fear of COVID-19 in Patients With Myocardial Infarction (Case Study: Shahid Madani Cardiac Hospital, Tabriz, Iran)
}

Fatemeh Golabi

Tabriz University: University of Tabriz

Mohammad Bagher Alizadeh Aghdam

Tabriz University: University of Tabriz

Mir Mojtaba Hosseini Mazraehshadi ( $\sim$ mojtabahosseinii1990@gmail.com )

Tabriz University: University of Tabriz https://orcid.org/0000-0002-0276-638X

Hamed Akbarian

Tabriz University: University of Tabriz

\section{Research}

Keywords: Quality of life, Myocardial infarction, Fear of COVID-19, WHOQOL-BREF, FCV-19S

Posted Date: October 11th, 2021

DOI: https://doi.org/10.21203/rs.3.rs-942305/v1

License: (a) This work is licensed under a Creative Commons Attribution 4.0 International License. Read Full License 


\section{Abstract}

Background: Quality of life is one of the most important concepts in the fields of health and development, and the study of its related factors can play an effective role in strengthening the quality of life. COVID-19 is one of the emerging crises in the world, and fear of it can affect the quality of life of people.

Purpose: The purpose of this study was to investigate the relationship between quality of life and fear of COVID-19 in patients with myocardial infarction.

Methods: In this study, we administered WHOQOL-BREF (World Health Organization quality of life questionnaire) and the Fear of COVID-19 Scale (FCV-19S) to 200 patients with myocardial infarction admitted to the hospital from February to April 2021. Then, we calculated the correlation between the quality of life and fear of COVID-19.

Results: The results of this study showed a moderate to high score in all domains of QoL and overall QoL among patients. The mean score of fear of COVID-19 was lower than average level. The research revealed that there was a negative correlation between fear of COVID-19 and physical health, environmental health, and overall quality of life $(p<0.05)$, but there was not a significant relationship between fear of coronavirus and psychological health and social relationships $(p>0.05)$. Furthermore, there were significant correlations between quality of life and sociodemographic variables including gender, age, marital status, and level of education. So that, female, widow(er), uneducated, and older patients had a lower quality of life.

Conclusions: Since the quality of life is one of the main indicators of health, managers must take strategies to improve the quality of life of people, especially patients. One of the measures that they can take is to reduce the fear of COVID-19 among patients by taking wise strategies.

\section{Introduction}

Quality of life (QoL) is a construct used increasingly frequently in the literature ([1, 2]. Definitions range from the philosophical to the pragmatic. QoL potentially encompasses a wide range of issues and the definition applied often reflects the perspective of the researcher or discipline; for example, defined at its most general it can be described as 'what the individual says it is' [3]. Other researchers emphasize the relative nature of QoL and have described it as 'the difference, or the gap, at a particular period of time, between the hopes and expectations of the individual and the individual's present experiences [4].

There is a considerable body of literature dedicated to the concept of quality of life. The review of various papers has revealed that there exist two common approaches to measuring the quality of life - the so-called "objective" and "subjective" approaches. This dichotomy is well illustrated in the Costanza R, Fisher B, Ali S, Beer C, Bond L, Boumans R, Danigelis NL, Dickinson J, Elliott C, Farley J, Gayer DE, Glenn LM, Hudspeth T, Mahoney D, McCahill L, McIntosh B, Reed B, Rizvi SAT, Rizzo DM, Simpatico T and Snapp R [5] paper where the authors point out that "QOL [quality of life] is proposed as a multi-scale, multi-dimensional concept that contains interacting objective and subjective elements." There seems to be a general agreement in the literature that the objective approach constitutes a method of assessing the quality of life that involves the use of aggregate indicators that represent a region as a whole, such as life expectancy at birth, average income, unemployment, etc. Such indicators measure factual states of certain social phenomena rather than abstract concepts such as people's attitudes or feelings and are normally calculated within systems of official statistics. On the other hand, the subjective approach of measuring the quality of life represents a method that relies on reported people's perceptions and involves assessments of attitudes and feelings of individuals aggregated to the scale of a particular territory. Such information usually comes from various types of public opinion polls [6].

The absence of a consensual definition led experts from 15 countries in an effort to develop a definition that would capture the fundamental characteristics of QoL. They defined it as:

"The individual's perception of his/her position in life in the context of the culture and value systems in which he/she lives and in relation to his/her goals, expectations, standards and concerns. It is a broad ranging concept affected in a complex way by the person's physical health, psychological state, level of independence, social relationships and their relationship to salient features of their environment"[7].

The need for a broader and more balanced QoL definition has resulted in widespread adoption of WHO's definition [8], as it seems to be one of the very few that takes into account the multidimensional nature of the concept. It includes dimensions above and beyond those described in the literature (e.g. [9], while taking into account the individuals' subjective evaluations and satisfaction with their life [10]. 
In January 2020, the World Health Organization (WHO) declared the coronavirus disease 2019 outbreak (COVID-19) an international public health emergency[11]. The global community continues to face high transmission rates of this unpredictable, fast-spreading infectious disease that presents serious challenges to global health [12].

Aiming to slow the spread of the virus, overload of healthcare systems and infection-related mortality, governments around the globe have implemented public health measures (such as isolation, quarantine, physical and social distancing) as fundamental infection control measures [13-16]. These unpleasant changes bring the perception of constrained freedom (sense of loss of control and being trapped, especially in those separated from family), increasing psychological distress and community anxiety $([15,17]$. The unpredictability of the situation makes people uncertain of how safe they are and how worried they should be, elevating fears and misconceptions [15].

\section{Background}

QoL assessment across various domains helps identify the range of problems that can influence people's everyday lives. Literature suggests that QoL is a significant predictor of persistence in overall health and well-being [18]. Outbreaks of infectious diseases, such as COVID-19, negatively affect the physical, social, and psychological functioning of individuals and societies, and have significant economic consequences $[19,20]$. A previous study from Hong Kong that assessed the health-related quality of life among survivors of the severe acute respiratory syndrome (SARS) six months after the start of the pandemic reported significant impairment in QoL for general health domains, physical conditions, and social functioning [21]. A recent study from Morocco reported negative effects of the COVID-19 pandemic on QoL

[22]. Implementing preventive measures affects people's daily life activities and certainly influences individuals' general functioning and wellbeing $[19,23]$. Previous research studied the negative psychological effects of quarantine after the SARS outbreak, and recent studies have introduced the term "coronaphobia" to describe stress and anxiety among general populations [24,25]. Mental health experts expressed concerns about the repercussions of the COVID-19 pandemic on communities' psychological functioning and well-being $[15,25]$. Though recent discussions in literature have cautioned about the broader psychological implications of massive quarantine to control COVID-19 spread on individuals' QoL [15], the empirical research on the effects of the COVID-19 pandemic on various dimensions of QoL in different countries is scarce.

Therefore, the aim of the current study was to investigate the quality of life and fear of COVID-19 in patients with myocardial infarction and determine the relationship between these two variables.

\section{Methods}

\section{Population and sample}

Patients with myocardial infarction admitted to Shahid Madani Cardiac Hospital constituted the target population of this study. The study sample was recruited by convenience sampling method and consisted of 200 patients with myocardial infarction admitted to the hospital from February to April 2021.

\section{Procedure}

Patients recruited for the study met the following conditions:

1. The diagnosis of myocardial infarction was noted in their medical record by the treating physician.

2. They were fully awake and were able to cooperate with the researcher to answer the questions.

3. They were physically fit to answer the questions.

Participation was voluntary, and all of the respondents were informed about the anonymity of the study and that they could stop answering the questions at any time and without giving any reason.

\section{Instruments}

\section{Sociodemographic information}

A sociodemographic questionnaire was used to collect information about gender, age, marital status, and level of education of the participants.

\section{The WHOQOL-BREF}


The validated WHOQOL-BREF (Persian version) was used to measure quality of life [26]. It consists of 26 items of which 24 were divided in four domains, including physical health (7 items), psychological health (6 items), social relationships (3 items), and environmental health (8 items), and two items on overall QoL and general health. The response options range from 1 (very dissatisfied/very poor) to 5 (very satisfied/very good) [27]. The obtained raw scores were transformed into a linear scale ranged from 0 to 100 to enable making comparisons between domains composed of unequal numbers of items [28].

\section{Fear of COVID-19 Scale (FCV-19S)}

The seven-item FCV-19S was developed to quickly assess individuals' fear towards COVID-19 [29, 30]. A total score is calculated by adding up each item score (ranging from 7 to 35). The higher the score, the greater the fear of coronavirus-19. Responding to items on a five-point Likert scale ( 1 = strongly disagree; 5 = strongly agree), the FCV-19S has been found to be psychometrically sound in assessing fear of COVID19 in different populations, including different ethnic groups and various vulnerable groups. A higher level of fear toward COVID-19 is indicated by the higher FCV-19S score [29].

\section{Data analysis}

Data was analyzed using SPSS software, version 26. Various statistical tests including Independent-Samples t-Test, one-way ANOVA, and Pearson's $r$ were used based on levels of measurement of the variables. A p value less than 0.05 was considered statistically significant.

\section{Results}

\section{Sample statistics}

Table 1 shows the sociodemographic characteristics of the respondents. In the current study, most of the participants were male ( $\mathrm{n}=170)$. The majority of the participants were married (89\%). The mean age was 57.11 years with a standard deviation of 11.35 . Moreover, $25 \%$ of the respondents had finished secondary school, and $25 \%$ of them had a diploma or associate degree.

Table 1

Sociodemographic characteristics of the participants $(n=200)$

\begin{tabular}{|lll|}
\hline Variables & N & $\%$ \\
\hline Age & & \\
\hline$\leq 45$ years & 30 & 15 \\
\hline $46-65$ years & 129 & 64.5 \\
\hline$>65$ years & 41 & 20.5 \\
\hline Gender & & \\
\hline Male & 170 & 85 \\
\hline Female & 30 & 15 \\
\hline Marital status & & \\
\hline Single & 7 & 3.5 \\
\hline Married & 178 & 89 \\
\hline Divorced & 4 & 2 \\
\hline Widow(er) & 11 & 5.5 \\
\hline Level of education & 50 & 25 \\
\hline Uneducated & 28 & 14 \\
\hline Primary school & 50.5 \\
\hline Secondary school & 25 \\
\hline Diploma or associate degree & 50 & \\
\hline Bachelor's degree or more & 25 & \\
\hline
\end{tabular}

Page 4/9 


\section{Quality of life}

The results revealed that the mean physical health, psychological health, social relationships, environmental health, and overall quality of life were $59.08 \pm 21.28,60.35 \pm 20.01,66.91 \pm 19.59,61.54 \pm 19.12$, and $59.29 \pm 15.65$, respectively.

The mean raw scores, mean transformed scores, and standard deviations for domains of WHOQOL-BREF are depicted in Table 2.

Table 2

Raw scores and transformed scores of QoL domains

\begin{tabular}{|lllll|}
\hline QoL domains & Mean raw scores & Standard deviation & Mean transformed scores $(\mathbf{0}-\mathbf{1 0 0})$ & Standard deviation \\
\hline Physical health & 23.54 & 5.96 & 59.08 & 21.28 \\
\hline Psychological health & 20.48 & 4.80 & 60.35 & 20.01 \\
\hline Social relationships & 11.03 & 2.35 & 66.91 & 19.59 \\
\hline Environmental health & 27.69 & 6.12 & 61.54 & 19.12 \\
\hline Overall QoL & 89.66 & 16.27 & 59.29 & 15.65 \\
\hline
\end{tabular}

\section{Fear of COVID-19}

The score of the fear of COVID-19 among patients is shown in Table 3. According to this table, the level of fear of COVID-19 among respondents of this research was less than average.

Table 3

Score of fear of COVID-19 among patients

\begin{tabular}{|lll|}
\hline Variable & Mean & Standard Deviation \\
\hline Fear of COVID-19 & 18.09 & 7.47 \\
\hline
\end{tabular}

\section{Correlation between sociodemographic variables and job burnout}

As shown in Table 4, there was a significant correlation between gender and physical health, social relationships, and overall quality of life; so that, male respondents obtained better scores in these dimensions and overall quality of life. Also, age and all of the domains of quality of life except environmental heath were negatively correlated; so that, as participants got older, their quality of life decreased. According to the table, there was a significant relationship between marital status and all domains of quality of life except environmental health. According to the results of the subsequent LSD test, the obtained scores of widow(er)s in physical health, psychological health, and overall quality of life were significantly less than single, married and divorced respondents. Besides, social relationships of widow(er)s and divorced participants were worse than single and married ones. There was a significant correlation between level of education and all domains of quality of life except social relationships; so that, respondents who had higher levels of education obtained better scores in QoL domains. 
Table 4

Correlation between sociodemographic variables and QoL domains

\begin{tabular}{|c|c|c|c|c|c|}
\hline Variables & Domain 1 & Domain 2 & Domain 3 & Domain 4 & Overall QoL \\
\hline \multicolumn{6}{|l|}{ Gender } \\
\hline Male & $60.44 \pm 21.15$ & $61.37 \pm 20.24$ & $68.72 \pm 18.48$ & $62.05 \pm 18.99$ & $60.45 \pm 15.43$ \\
\hline Female & $51.42 \pm 20.75$ & $54.58 \pm 17.92$ & $56.66 \pm 22.67$ & $58.64 \pm 19.91$ & $52.69 \pm 15.49$ \\
\hline $\mathrm{p}$ value & $0.032 *$ & 0.087 & $0.002^{\star *}$ & 0.369 & $0.012^{*}$ \\
\hline \multicolumn{6}{|l|}{ Age } \\
\hline Pearson correlation & -0.192 & -0.142 & -0.163 & -0.034 & -0.166 \\
\hline $\mathrm{p}$ value & $0.007 * \star$ & $0.046 *$ & 0.021 * & 0.636 & $0.019 *$ \\
\hline \multicolumn{6}{|l|}{ Marital status } \\
\hline Single & $73.97 \pm 12.66$ & $73.21 \pm 14.99$ & $76.19 \pm 12.19$ & $67.85 \pm 12.33$ & $69.91 \pm 8.96$ \\
\hline Married & $59.37 \pm 21.01$ & $60.67 \pm 20.07$ & $68.30 \pm 18.64$ & $61.56 \pm 19.07$ & $59.73 \pm 15.25$ \\
\hline Divorced & $78.57 \pm 11.29$ & $67.70 \pm 12.44$ & $45.83 \pm 25.00$ & $75.00 \pm 12.23$ & $67.54 \pm 6.99$ \\
\hline Widow(er) & $37.98 \pm 16.38$ & $44.31 \pm 15.50$ & $46.21 \pm 21.52$ & $52.27 \pm 22.53$ & $42.39 \pm 16.50$ \\
\hline$p$ value & $0.000 * *$ & $0.014 *$ & $0.000 * *$ & 0.149 & $0.000 * \star$ \\
\hline \multicolumn{6}{|l|}{ Level of education } \\
\hline Uneducated & $48.08 \pm 18.67$ & $52.23 \pm 21.82$ & $61.90 \pm 17.48$ & $45.31 \pm 17.54$ & $47.87 \pm 16.60$ \\
\hline Primary school & $59.27 \pm 22.16$ & $60.54 \pm 18.79$ & $62.23 \pm 20.91$ & $59.17 \pm 17.94$ & $57.97 \pm 13.30$ \\
\hline Secondary school & $58.64 \pm 21.47$ & $57.33 \pm 18.33$ & $69.16 \pm 20.29$ & $61.56 \pm 17.33$ & $59.00 \pm 14.01$ \\
\hline Diploma or associate degree & $61.50 \pm 22.72$ & $64.75 \pm 20.27$ & $69.50 \pm 19.09$ & $66.87 \pm 17.91$ & $63.09 \pm 16.63$ \\
\hline Bachelor's degree or more & $67.14 \pm 14.35$ & $66.33 \pm 20.26$ & $71.66 \pm 17.17$ & $73.50 \pm 16.56$ & $67.53 \pm 12.62$ \\
\hline $\mathrm{p}$ value & $0.018 *$ & $0.033^{\star}$ & 0.110 & $0.000 * *$ & $0.000 * *$ \\
\hline
\end{tabular}

\section{Correlation between the fear of COVID-19 and quality of life}

Pearson correlation was computed to see the relationship between quality of life and fear of COVID-19 (Table 5). According to the table, there was a significant and negative correlation between fear of Coronavirus and physical health, environmental health, and overall quality of life; so that, by increasing the fear of COVID-19, the scores of physical health, environmental health, and overall quality of life decreased.

Table 5

Relationship between fear of COVID-19 and domains of QoL

\begin{tabular}{|lllllll|}
\hline Independent variable & Pearson's $\mathbf{r}$ & Domain 1 & Domain 2 & Domain 3 & Domain 4 & Overall QoL \\
\hline Fear of COVID-19 & Pearson correlation & -0.317 & -0.083 & -0.055 & -0.187 & -0.242 \\
\cline { 2 - 6 } & p value & $0.000^{\star *}$ & 0.245 & 0.441 & $0.008^{\star *}$ & $0.001^{\star \star}$ \\
\hline
\end{tabular}

\section{Discussion}

\section{Quality of life}

The results of this study showed a moderate to high score of quality of life among patients with myocardial infarction. The scores of QoL domains among participants of this study were similar to those of Komalasari R, Nurjanah and Yoche MM [31], who measured the quality of life of patients with a history of cardiovascular diseases. In comparison, Lamesgin Endalew H, Liyew B, Kassew T, Ewnetu Tarekegn G, Dejen Tilahun A and Sewunet Alamneh T [32] reported moderate to low quality of life among MI patients. 


\section{Fear of COVID-19}

The mean score of fear of COVID-19 among patients with myocardial infarction was lower than average. The score of fear of COVID-19 among respondents of this study was similar to those of Haghbin M, Abbasi A, Rafei E, Kheradmand A, Javdani F, Hatami N, Afraz P and Kalani N [33], who measured the fear of Coronavirus in breast cancer patients.

\section{Relationship between fear of COVID-19 and quality of life}

In the present study, there was a negative relationship between fear of Coronavirus and physical health, environmental health, and overall quality of life. The findings of this research were in line with the findings of Ferreira LN, Pereira LN, da Fé Brás M and Ilchuk K [34] and Khojasteh Rad a, Mohammadkhah f, Amjadi s and Navabi N [35], who reported that people with more COVID-19 anxiety had poorer quality of life.

\section{Conclusion}

Since the present study has found a significant correlation between fear of COVID-19 and quality of life among patients with myocardial infarction, the following measures are suggested to reduce the prevalence of COVID-19 and thus improve the quality of life of patients:

- Educating patients on taking the essential precautions against the coronavirus.

- Providing the required hygienic equipment like face masks and hand sanitisers for all of the patients

- Accelerating the process of vaccinating people against COVID-19, and consequently, reducing the incidence of coronavirus.

Moreover, findings of the correlation between sociodemographic variables and quality of life indicated that female, widow(er), uneducated, and older patients had a lower quality of life. As a result, the government should take wise strategies to improve the quality of life of these patients.

\section{Declarations}

\section{Ethical Approval and Consent to participate:}

The study was approved by University of Tabriz (Biomedical Research Ethics Committee). Besides, all the patients provided written informed consent to participate in the study.

\section{Availability of supporting data:}

The data that support the findings of this study are available on request from the corresponding author.

\section{Competing interests:}

Prof. Golabi is a professor of sociology and Dr. Alizadeh Aghdam is the head of the sociology department at the University of Tabriz. Mr. Hosseini and Mr. Akbarian are master's students in sociology. The present study was conducted under the guidance of Prof. Golabi and Dr. Alizadeh Aghdam.

\section{Funding:}

The current study did not have any funding sources.

\section{Authors' contributions:}

FG and MBAA designed the research study. HA distributed the questionnaires among the patients and collected the data. MMHM analyzed the data and wrote the paper and FG, MBAA, and HA edited the manuscript. All authors read and approved the final manuscript.

\section{Acknowledgements:}

The authors would like to thank all the patients with myocardial infarction who participated in this study.

\section{References}


1. Albrecht GL: Subjective health assessment. Measuring health and medical outcomes 1994:7-26. https://books.google.com/books? id=gSSMAQAAQBAJ\&lpg=PA7\&ots=kz82hBp4aC\&dq=Albrecht\%2C\%20G.\%20L.\%20(1994)\&lr=lang_en\&pg=PA98\#v=onepage\&q\&f=false

2. Kaptein AA, Weinman J: Health Psychology. Wiley; 2004, https://books.google.co.uk/books?id=BjV4RAAACAAJ

3. Joyce C: Quality of life: the state of the art in clinical assessment. Quality of life assessment and application 1988:119-169.

4. Calman KC: Quality of life in cancer patients-an hypothesis. Journal of Medical Ethics 1984, 10:124. https://doi.org/10.1136/jme.10.3.124

5. Costanza R, Fisher B, Ali S, Beer C, Bond L, Boumans R, Danigelis NL, Dickinson J, Elliott C, Farley J, et al: Quality of life: An approach integrating opportunities, human needs, and subjective well-being. Ecological Economics 2007, 61:267-276.

https://doi.org/https://doi.org/10.1016/j.ecolecon.2006.02.023

6. Safonov TA: A New Measure of Quality of Life and Its Application in the Regions of the Russian Federation. Western Illinois University; 2015, https://www.proquest.com/docview/1719102533?pq-origsite=gscholar\&fromopenview=true

7. The WHOQOL Group: Development of the WHOQOL: Rationale and Current Status. International Journal of Mental Health 1994, 23:2456. https://doi.org/10.1080/00207411.1994.11449286

8. Bowling A: Current state of the art in quality of life measurement. In Quality of Life. Edited by Carr A, Higginson I, Robinson P. London: BMJ Books; 2002, https://eprints.soton.ac.uk/334682/

9. Cella DF: Quality of life: concepts and definition. J Pain Symptom Manage 1994, 9:186-192. https://doi.org/10.1016/08853924(94)90129-5

10. The WHOQOL Group: The World Health Organization Quality of Life assessment (WHOQOL): position paper from the World Health Organization. Soc Sci Med 1995, 41:1403-1409. https://doi.org/10.1016/0277-9536(95)00112-k

11. Hayn D, Schreier G, Baumgartner M: Navigating Healthcare Through Challenging Times: Proceedings of DHealth 2021 - Health Informatics Meets Digital Health. IOS Press; 2021, https://books.google.com/books?id=h0AvEAAAQBAJ

12. Mamun MA, Griffiths MD: First COVID-19 suicide case in Bangladesh due to fear of COVID-19 and xenophobia: Possible suicide prevention strategies. Asian Journal of Psychiatry 2020, 51:102073. https://doi.org/https://doi.org/10.1016/j.ajp.2020.102073

13. Dsouza DD, Quadros S, Hyderabadwala ZJ, Mamun MA: Aggregated COVID-19 suicide incidences in India: Fear of COVID-19 infection is the prominent causative factor. Psychiatry Research 2020, 290:113145. https://doi.org/https://doi.org/10.1016/j.psychres.2020.113145

14. Lai C-C, Shih T-P, Ko W-C, Tang H-J, Hsueh P-R: Severe acute respiratory syndrome coronavirus 2 (SARS-CoV-2) and coronavirus disease2019 (COVID-19): The epidemic and the challenges. International Journal of Antimicrobial Agents 2020, 55:105924.

https://doi.org/https://doi.org/10.1016/j.ijantimicag.2020.105924

15. Rubin GJ, Wessely S: The psychological effects of quarantining a city. BMJ 2020, 368:m313. https://doi.org/10.1136/bmj.m313

16. Tull MT, Edmonds KA, Scamaldo KM, Richmond JR, Rose JP, Gratz KL: Psychological Outcomes Associated with Stay-at-Home Orders and the Perceived Impact of COVID-19 on Daily Life. Psychiatry Research 2020, 289:113098.

https://doi.org/https://doi.org/10.1016/j.psychres.2020.113098

17. Brooks SK, Webster RK, Smith LE, Woodland L, Wessely S, Greenberg N, Rubin GJ: The psychological impact of quarantine and how to reduce it: rapid review of the evidence. The Lancet 2020, 395:912-920. https://doi.org/https://doi.org/10.1016/S0140-6736(20)30460-8

18. Fayers PM, Machin D: Quality of Life: The Assessment, Analysis and Interpretation of Patient-reported Outcomes. Wiley; 2013, https://books.google.com/books?id=pqX6WKgHKJsC

19. Qiu J, Shen B, Zhao M, Wang Z, Xie B, Xu Y: A nationwide survey of psychological distress among Chinese people in the COVID-19 epidemic: implications and policy recommendations. General Psychiatry 2020, 33:e100213. https://doi.org/10.1136/gpsych-2020100213

20. Yezli S, Khan A: COVID-19 social distancing in the Kingdom of Saudi Arabia: Bold measures in the face of political, economic, social and religious challenges. Travel Medicine and Infectious Disease 2020, 37:101692.

https://doi.org/https://doi.org/10.1016/j.tmaid.2020.101692

21. Algahtani FD, Hassan S-U-N, Alsaif B, Zrieq R: Assessment of the Quality of Life during COVID-19 Pandemic: A Cross-Sectional Survey from the Kingdom of Saudi Arabia. International journal of environmental research and public health 2021, 18:847. https://doi.org/10.3390/ijerph18030847

22. Mucci F, Mucci N, Diolaiuti F: Lockdown and isolation: psychological aspects of COVID-19 pandemic in the general population. Clinical Neuropsychiatry 2020, 17:63-64. https://doi.org/https://doi.org/10.36131/CN20200205

23. Mazza C, Ricci E, Biondi S, Colasanti M, Ferracuti S, Napoli C, Roma P: A Nationwide Survey of Psychological Distress among Italian People during the COVID-19 Pandemic: Immediate Psychological Responses and Associated Factors. International Journal of Environmental Research and Public Health 2020, 17:3165. https://www.mdpi.com/1660-4601/17/9/3165

Page $8 / 9$ 
24. Hawryluck L, Gold WL, Robinson S, Pogorski S, Galea S, Styra R: SARS control and psychological effects of quarantine, Toronto, Canada. Emerging infectious diseases 2004, 10:1206-1212. https://doi.org/10.3201/eid1007.030703

25. Asmundson GJG, Taylor S: Coronaphobia: Fear and the 2019-nCoV outbreak. J Anxiety Disord 2020, 70:102196. https://doi.org/10.1016/j.janxdis.2020.102196

26. Nejat S, Montazeri A, Holakouie Naieni K, Mohammad K, Majdzadeh SR: The World Health Organization quality of Life (WHOQOL-BREF) questionnaire: Translation and validation study of the Iranian version. Journal of School of Public Health and Institute of Public Health Research 2006, 4:1-12. http://sjsph.tums.ac.ir/article-1-187-fa.html

27. World Health Organization: Programme on mental health: WHOQOL user manual. World Health Organization; 1998, https://apps.who.int/iris/bitstream/handle/10665/77932/WHO_HIS_HSI_Rev.2?sequence=1

28. The WHOQOL Group: Development of the World Health Organization WHOQOL-BREF Quality of Life Assessment. Psychological Medicine 1998, 28:551-558. https://doi.org/10.1017/S0033291798006667

29. Ahorsu DK, Lin C-Y, Imani V, Saffari M, Griffiths MD, Pakpour AH: The Fear of COVID-19 Scale: Development and Initial Validation. International Journal of Mental Health and Addiction 2020. https://doi.org/10.1007/s11469-020-00270-8

30. Ahorsu DK, Lin C-Y, Pakpour AH: The Association Between Health Status and Insomnia, Mental Health, and Preventive Behaviors: The Mediating Role of Fear of COVID-19. Gerontology and Geriatric Medicine 2020, 6:2333721420966081.

https://doi.org/10.1177/2333721420966081

31. Komalasari R, Nurjanah, Yoche MM: Quality of Life of People with Cardiovascular Disease: A Descriptive Study. Asian/Pacific /sland nursing journal 2019, 4:92-96. https://doi.org/10.31372/20190402.1045

32. Lamesgin Endalew H, Liyew B, Kassew T, Ewnetu Tarekegn G, Dejen Tilahun A, Sewunet Alamneh T: Health-Related Quality of Life Among Myocardial Infarction Survivors: Structural Equation Modeling Approach. Journal of multidisciplinary healthcare 2021, 14:15431552. https://doi.org/10.2147/JMDH.S296064

33. Haghbin M, Abbasi A, Rafei E, Kheradmand A, Javdani F, Hatami N, Afraz P, Kalani N: Anxiety caused by new coronavirus (Covid-19) in breast cancer patients during the coronavirus pandemic. The Iranian Journal of Obstetrics, Gynecology and Infertility 2020, 23:8-17. https://doi.org/10.22038/ijogi.2020.17286

34. Ferreira LN, Pereira LN, da Fé Brás M, Ilchuk K: Quality of life under the COVID-19 quarantine. Quality of Life Research 2021, 30:13891405. https://doi.org/10.1007/s11136-020-02724-x

35. Khojasteh Rad a, Mohammadkhah f, Amjadi s, Navabi N: Relationship of Corona Anxiety with Life Satisfaction and Quality of Life in Iranian Adults. mubabol-cjhaa 2021, 5:0-0. http://cjhaa.mubabol.ac.ir/article-1-126-fa.html 